\title{
Synthetic approaches to difluoroindolecarboxylic acid ethyl esters
}

\author{
Romano Silvestri,* Marino Artico, Giuseppe La Regina, and Gabriella De Martino \\ Istituto Pasteur - Fondazione Cenci Bolognetti, Dipartimento di Studi Farmaceutici, \\ Università degli Studi di Roma “La Sapienza”, P.le Aldo Moro 5, I-00185 Roma, Italy \\ E-mail: romano.silvestri@uniroma1.it
}

\section{On the occasion of the Fuori Ruolo position of Professor Vincenzo Tortorella}

(received 13 Oct 03; accepted 12 Dec 03; published on the web 27 Dec 03)

\begin{abstract}
Synthetic approaches to ethyl 4,5-difluoroindole-2-carboxylate and ethyl 5,6-difluoroindole-2carboxylate by Fischer indole synthesis and by the reaction of lithiated $\mathrm{N}$-BOC-3,4-difluoro-2methylaniline with diethyl oxalate or ethyl bromopyruvate were investigated. A simple and direct preparation of ethyl 4,5-difluoroindole-3-carboxylate from lithiated $\mathrm{N}$-BOC-3,4difluoroaniline and ethyl bromopyruvate was found.
\end{abstract}

Keywords: Indolecarboxylate, heterocyclic, synthesis

\section{Introduction}

A search on anti-HIV-1 agents led us to investigate the structure-activity relationships (SARs) of various indolyl aryl sulfones (IASs) related to Merck NNRT agent L-737,126 $\mathbf{1}^{1}$ (Figure 1).

In order to improve the antiviral activity of $\mathbf{1}$ against wt-HIV-1 and some clinically relevant strains of resistant mutants, we planned the synthesis of IAS derivatives having a 4,5difluorosubstituted indole nucleus. Such a substitution performed on bicyclic heterocycles related to efavirenz 2 led to DCP 9633 and DCP 082 4, two derivatives endowed with potent antiviral activity against various resistant mutants. ${ }^{2,3}$

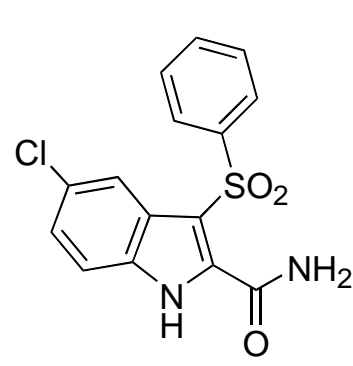

$\mathrm{L}-737,126(1)$

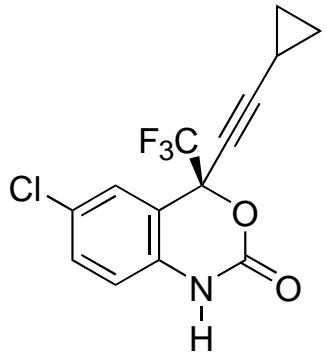

Efavirenz (2)

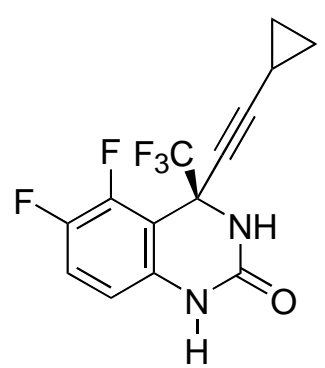

DCP $963(3)$

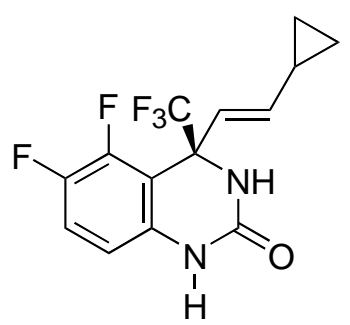

DCP $082(4)$

\section{Figure 1}




\section{Results and Discussion}

The approach to 4,5-difluorosubstituted IASs required the ethyl ester of 4,5-difluoroindole-2carboxylic acid $\mathbf{5}$ as starting material. To our knowledge, the preparation of $\mathbf{5}$, and the related 5,6-difluoroanalog 6, have been reported in patents only. 4,5

As a first approach, we attempted to prepare 5 by the standard Fischer indole synthesis. ${ }^{6}$ Reaction of 3,4-difluoroaniline according to Japp-Klingemann method ${ }^{7}$ furnished the 3,4difluorophenyl hydrazone of ethyl pyruvate 7, which was converted to a mixture of $\mathbf{5}$ and $\mathbf{6}$ by heating with polyphosphoric acid (PPA) ${ }^{8}$ (Scheme 1). The isomeric mixture was separated by repeated passages on chromatography column to afford pure $5(15 \%)$ and 6 (22\%).

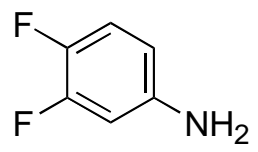

1. $\mathrm{NaNO}_{2}, \mathrm{HCl}$
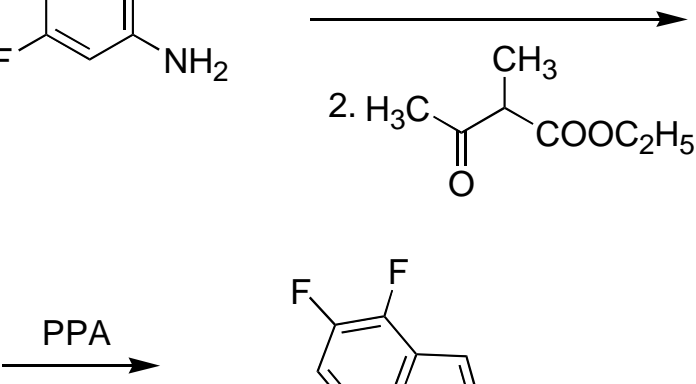

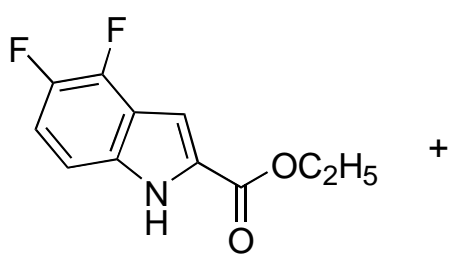

5<smiles>CCOC(=O)/C(C)=N/Nc1ccc(F)c(F)c1</smiles>

7<smiles>CCOC(=O)c1cc2cc(F)c(F)cc2[nH]1</smiles>

6

\section{Scheme 1}

The low overall yield obtained with the Fischer method and the difficulties encountered in the separation/purification of isomers 5 and $\mathbf{6}$, prompted us to synthesize the required 4,5difluoroderivative 5 by the procedure reported by Clark, ${ }^{9}$ and later by Allen, ${ }^{10}$ concerning the synthesis of indole-2-carboxylic acid esters by lateral lithiation of $N$-BOC-protected toluidines.

We therefore treated $\mathrm{N}$-BOC-2-methyl-3,4-difuoroaniline, prepared by the reaction between lithiated $N$-BOC-3,4-difluoroaniline and iodomethane, ${ }^{11}$ with 2 equivalents of sec-BuLi at $-40^{\circ} \mathrm{C}$ as reported by Clark, ${ }^{9}$ and then with diethyl oxalate (Scheme 2). After quenching, the proposed intermediate hydroxy ester $\mathbf{8}$ was treated with trifluoroacetic acid to afford 5 in $8 \%$ yield.

This procedure gave overall yield considerably lower than those reported by Allen ${ }^{10}$ for monofluoroindoles. We can argue that the presence of the fluorine atom ortho to the methyl group of toluidine would reduce dramatically the reactivity of the lithiated $\mathrm{N}$-BOC-3,4-difluoro2-methylaniline. This result was supported by the fact that $\mathrm{N}$-BOC-2-methyl-6-fluoroaniline underwent easily lateral lithiation (sec-BuLi, THF, $\left.-40{ }^{\circ} \mathrm{C}\right),{ }^{10}$ whereas the isomeric $N$-BOC-2methyl-5-fluoroaniline failed to undergo lithiation. ${ }^{12}$ 


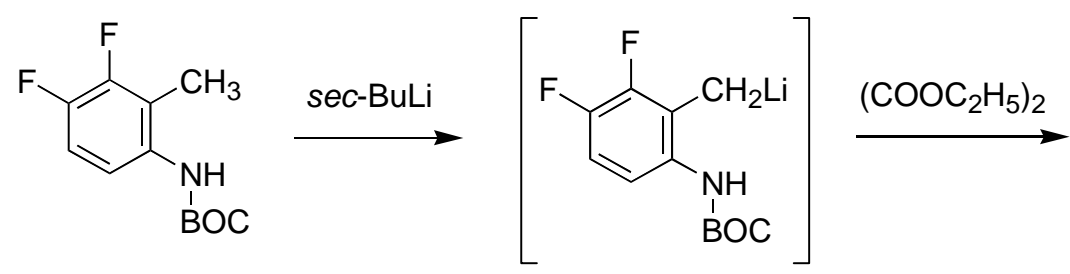

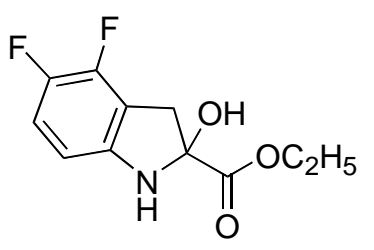

8

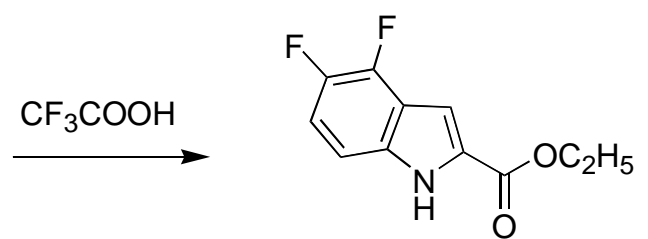

5

\section{Scheme 2}

In order to improve the yield of required indole ester, we attempted to prepare 5 by reacting lithiated $N$-BOC-3,4-difluoroaniline with ethyl bromopyruvate. Contrary to our expectations, ethyl 4,5-difluoroindole-3-carboxylate 12 was the sole product obtained from this reaction (Scheme 3). This result was probably due to the formation of the intermediate 9 as a consequence of the reaction of the lithiated C-2 with the ketone group of pyruvate instead of with the bromomethyl group (intermediate 10). ${ }^{13}$

It is noteworthy that the one-pot preparation of ethyl 4,5-difluoroindole-3-carboxylate 12 (Scheme 3) is a very simple and more convenient procedure compared to other standard synthetic methods requiring 3-lithium-1-(phenylsulfonyl)indole as intermediate, ${ }^{14}$ or based on Grignard reaction of indole ring with ethyl chloroformate. ${ }^{15}$

\section{Experimental Section}

General Procedures. Melting points (mp) were determined on a Büchi 510 apparatus and are uncorrected. Infrared spectra (IR) were run on Perkin-Elmer 1310 and SpectrumOne spectrophotometers. Band position and absorption ranges are given in $\mathrm{cm}^{-1}$. Proton nuclear magnetic resonance ( ${ }^{1} \mathrm{H}$ NMR) spectra were recorded on Bruker AM-200 (200 MHz) and Bruker Advance $400 \mathrm{MHz}$ FT spectrometers in the indicated solvent. Chemical shifts are expressed in units (ppm) from tetramethylsilane. Column chromatographies were packed with alumina Merck (70-230 mesh) and silica gel Merck (70-230 mesh). Aluminum oxide TLC cards Fluka (aluminum oxide precoated aluminum cards with fluorescent indicator at $254 \mathrm{~nm}$ ) and silica gel TLC cards Fluka (silica gel precoated aluminum cards with fluorescent indicator at $254 \mathrm{~nm}$ ) were used for thin layer chromatography (TLC). Developed plates were visualized by Spectroline ENF 260C/F UV apparatus. Organic solutions were dried over anhydrous sodium sulfate. Concentration and evaporation of the solvent after reaction or extraction was carried out 
on a rotary evaporator Büchi Rotavapor operating at reduced pressure. Elemental analyses were found within $\pm 0.4 \%$ of the theoretical values.<smiles>CC(=O)Nc1ccc(F)c(F)c1</smiles>
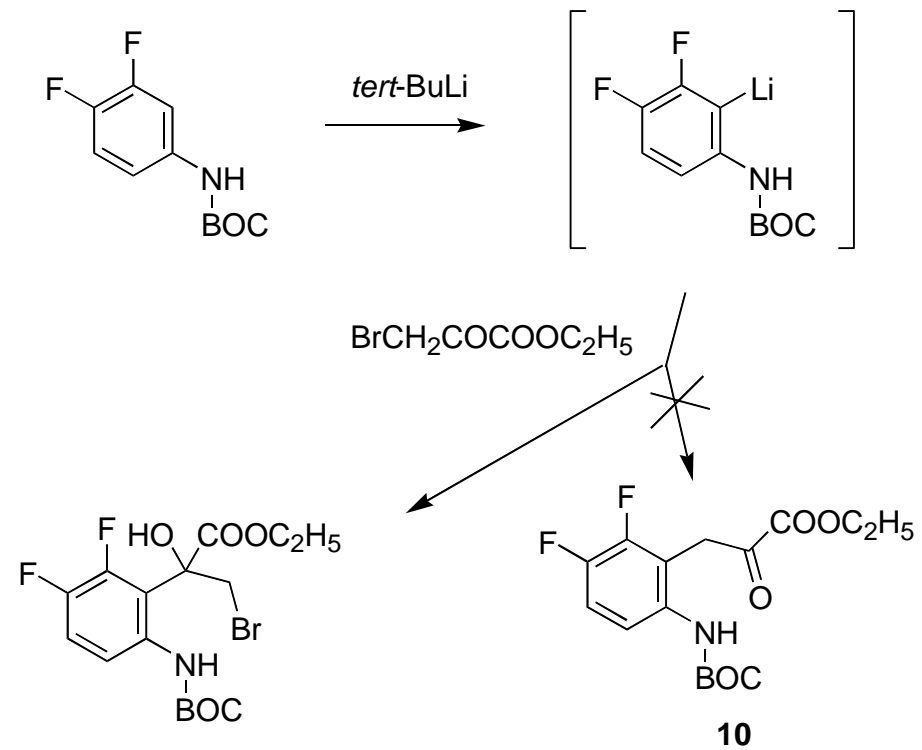

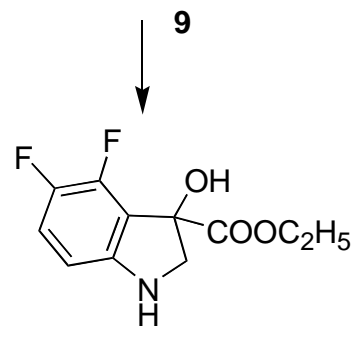

11

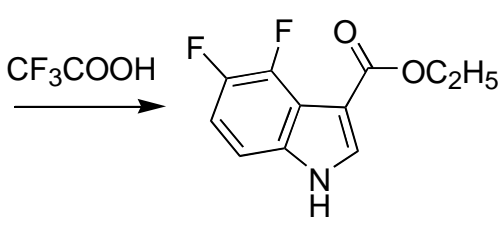

12

\section{Scheme 3}

Ethyl pyruvate 3,4-difluorophenylhydrazone (7). To an ice-cooled mixture of 3,4difluoroaniline $(20.9 \mathrm{~g}, 0.16 \mathrm{~mol}), 37 \% \mathrm{HCl}(39 \mathrm{~mL})$ and water $(39 \mathrm{~mL})$ was dropped a solution of sodium nitrite $(11.2 \mathrm{~g}, 0.16 \mathrm{~mol})$ in water $(14.7 \mathrm{~mL})$. Stirred was maintained on ice-bath for $20 \mathrm{~min}$, then sodium acetate trihydrate $(18.2 \mathrm{~g}, 0.22 \mathrm{~mol})$ was added and the resulting mixture was added to an ice-cooled well-stirred solution of ethyl 2-methylacetoacetate $(90 \%, 25.6 \mathrm{~g}$, $0.162 \mathrm{~mol})$, potassium acetate $(31.7 \mathrm{~g}, 0.32 \mathrm{~mol})$ in methanol $(157 \mathrm{~mL})$. The reaction was stirred at $0{ }^{\circ} \mathrm{C}$ for $3 \mathrm{~h}$, and then extracted with diethyl ether. The organic layer was separated, washed with brine and dried. Evaporation of the solvent gave a red oily residue which was dissolved in ethanol $(250 \mathrm{~mL})$ and stirred at room-temperature for 3 days. The resulting suspension was cooled at $4{ }^{\circ} \mathrm{C}$ overnight and then filtered to afford $16.0 \mathrm{~g}$ of 7 as a red salmon solid. The mother solution was concentrated in vacuo and, again, cooled at $4{ }^{\circ} \mathrm{C}$ and filtered to furnish additional $4.9 \mathrm{~g}$ of product. Overall yield of 7 was $20.9 \mathrm{~g}(53 \%), \mathrm{mp} 112-114{ }^{\circ} \mathrm{C}$, after crystallization from ethanol. ${ }^{1} \mathrm{H}$ NMR (DMSO-d $\left.)_{6}\right): \delta 1.26(\mathrm{t}, \mathrm{J}=7.1 \mathrm{~Hz}, 3 \mathrm{H}), 2.05(\mathrm{~s}, 3 \mathrm{H}), 4.20(\mathrm{q}, \mathrm{J}=7.1 \mathrm{~Hz}), 6.95-$ $7.45(\mathrm{~m}, 3 \mathrm{H}), 9.97 \mathrm{ppm}$ (broad s, $1 \mathrm{H}$, disappeared on treatment with $\mathrm{D}_{2} \mathrm{O}$ ). IR (nujol): $v 760$, $815,1110,1130,1180,1200,1300,3495,4050 \mathrm{~cm}^{-1}$. Anal. Calcd. For $\mathrm{C}_{11} \mathrm{H}_{12} \mathrm{~F}_{2} \mathrm{~N}_{2} \mathrm{O}_{2}(242.22)$ : C, 54.54; H, 4.99; N, 11.57; F, 15.69. Found: C, 54.37; H, 4.91; N, 11.50; F, 15.54. 
Ethyl 4,5-difluoroindole-2-carboxylate (5) and ethyl 5,6-difluoroindole-2-carboxylate (6). From 7. To PPA (160 g) pre-heated at $110{ }^{\circ} \mathrm{C}$ was added portionwise ethyl pyruvate 3,4 difluorophenylhydrazone 7 (16.0 g, $0.066 \mathrm{~mol})$, then reaction was maintained under stirring for $30 \mathrm{~min}$. After cooling at room temperature, crushed ice was added while stirring, and the solid which formed was separated by suction, washed with water and dried. The isomers were separated by repeated silica gel column chromatographies ( $n$-hexane / ethyl acetate 2:1 as eluent). First eluates afforded ethyl 5,6-difluoroindole-2-carboxylate 6, (3.3 g, 22 \%), mp 172$173{ }^{\circ} \mathrm{C}$, after crystallization from ethanol. ${ }^{1} \mathrm{H}$ NMR (DMSO-d $): \delta 1.33(\mathrm{t}, J=7.1 \mathrm{~Hz}, 3 \mathrm{H}), 4.34$ $(\mathrm{q}, J=7.1 \mathrm{~Hz}, 2 \mathrm{H}), 7.14(\mathrm{~m}, 1 \mathrm{H}), 7.36(\mathrm{ddd}, J=0.7,8.1$ and $11.0 \mathrm{~Hz}, 1 \mathrm{H}), 7.66(\mathrm{dd}, J=8.1$ and $11.0 \mathrm{~Hz}, 1 \mathrm{H}$ ), $12.07 \mathrm{ppm}$ (broad s, $1 \mathrm{H}$, disappeared on treatment with $\mathrm{D}_{2} \mathrm{O}$ ). IR (nujol): $v 770$, 865, 1020, 1220, 1240, 1290, 1690, $3600 \mathrm{~cm}^{-1}$. Anal. Calcd. For $\mathrm{C}_{11} \mathrm{H}_{9} \mathrm{~F}_{2} \mathrm{NO}_{2}$ (225.19): C, 58.67; H, 4.03; N, 6.22; F, 16.87. Found: C, 58.55; H, 3.98; N, 6.16; F, 16.79.

Further elution with the same eluent afforded ethyl 4,5-difluoroindole-2-carboxylate 5, (2.2 g, $15 \%$ ), mp 166-168 ${ }^{\circ} \mathrm{C}$, after crystallization from ethanol. ${ }^{1} \mathrm{H}$ NMR (DMSO-d $\left.\mathrm{d}_{6}\right): \delta 1.34(\mathrm{t}, J=$ $7.0 \mathrm{~Hz}, 3 \mathrm{H}), 4.35$ (q, $J=7.0 \mathrm{~Hz}, 2 \mathrm{H}), 7.20$ (m, 1H), 7.30-7.32 (m, 2H), 12.30 ppm (broad s, 1H, disappeared on treatment with $\mathrm{D}_{2} \mathrm{O}$ ). IR (nujol): $v 765,1020,1220,1255,1690,3600 \mathrm{~cm}^{-1}$. Anal. Calcd. For $\mathrm{C}_{11} \mathrm{H}_{9} \mathrm{~F}_{2} \mathrm{NO}_{2}$ (225.19): C, 58.67; H, 4.03; N, 6.22; F, 16.87. Found: C, 58.48; H, 3.97; N, 6.07; F, 16.61.

Ethyl 4,5-difluoroindole-2-carboxylate (5) from N-tert-butoxycarbonyl-2-methyl-3,4difluoroaniline. sec-Buthyl lithium $(3.22 \mathrm{~mL}$ of a $1.4 \mathrm{M}$ solution in pentane, $0.0045 \mathrm{~mol})$ was added dropwise to a solution of $N$-tert-butoxycarbonyl-2-methyl-3,4-difluoroaniline ${ }^{11}(0.50 \mathrm{~g}$, $0.002 \mathrm{~mol})$ in anhydrous THF $(7.2 \mathrm{~mL})$ at $-40{ }^{\circ} \mathrm{C}$. Temperature of solution was carefully maintained below $-20{ }^{\circ} \mathrm{C}$ and, after cooling at $-40{ }^{\circ} \mathrm{C}$ for $5 \mathrm{~min}$, a solution of diethyl oxalate $(0.35 \mathrm{~g}, 0.0025 \mathrm{~mol})$ in anhydrous THF $(2 \mathrm{~mL})$ was added. Reaction was slowly heated at $0{ }^{\circ} \mathrm{C}$, and then kept for $1 \mathrm{~h}$ under stirring. After quenching with ice water, diethyl ether was added while shaking. The organic layer was separated, washed with brine ad dried. Removal of the solvent gave a residue containing the hydroxy-ester $\mathbf{8}$, which was dissolved in dichloromethane $(10 \mathrm{~mL})$ and treated with trifluoroacetic acid $(2 \mathrm{~mL})$ for $20 \mathrm{~min}$ at room temperature. After dilution with diethyl ether and water, the organic layer was washed with brine and dried. Evaporation of the solvent gave a residue which was purified on silica gel column chromatography ( $n$-hexane / ethyl acetate $3: 1$ as eluent) to afford $5,37 \mathrm{mg}, 8 \%$, chemicophysical and spectral data were identical to those of the product prepared starting from 7 .

Ethyl 4,5-difluoroindole-3-carboxylate (12). tert-Butyl lithium (21.2 mL of a $1.7 \mathrm{M}$ solution in pentane, $0.033 \mathrm{~mol}$ ) was slowly added by a syringe to a solution of $N$-(tert-butoxycarbonyl)-3,4difluoroaniline $^{11}(3.4 \mathrm{~g}, 0.015 \mathrm{~mol})$ in anhydrous $\mathrm{THF}(40 \mathrm{~mL})$ at $-78{ }^{\circ} \mathrm{C}$ under argon atmosphere. After stirring for $1 \mathrm{~h}$ at $-78{ }^{\circ} \mathrm{C}$, ethyl bromopyruvate $(2.92 \mathrm{~g}, 0.015 \mathrm{~mol})$ was added and the reaction was gradually heated to $0{ }^{\circ} \mathrm{C}$ in about $2 \mathrm{~h}$ while stirring. Ethyl acetate and water were added while stirring. The organic layer was separated, washed with brine and dried. Removal of the solvent gave an orange oily residue which was refluxed in xylene $(10 \mathrm{~mL})$ containing trifluoroacetic acid $(2 \mathrm{~mL})$ for $2 \mathrm{~h}$. After dilution with diethyl ether and water, the 
organic layer was washed with brine and dried. Evaporation of the solvent gave a residue which was purified on silica gel column chromatography ( $n$-hexane / ethyl acetate 3:1 as eluent) to afford 12, $0.88 \mathrm{~g}, 26 \%$, mp $115-118{ }^{\circ} \mathrm{C}$, after crystallization from ethanol. ${ }^{1} \mathrm{H} \mathrm{NMR}\left(\mathrm{CDCl}_{3}\right): \delta$ $1.40(\mathrm{t}, J=7.1 \mathrm{~Hz}, 3 \mathrm{H}), 4.37$ (q, $J=7.1 \mathrm{~Hz}, 2 \mathrm{H}), 7.10(\mathrm{~m}, 2 \mathrm{H}), 7.95(\mathrm{~m}, 1 \mathrm{H}), 8.80$ ppm (broad s, $1 \mathrm{H}$, disappeared on treatment with $\mathrm{D}_{2} \mathrm{O}$ ). IR (nujol): $v$ 800, 1021, 1081, 1208, 1261, 1694, $3268 \mathrm{~cm}^{-1}$. Anal. Calcd. For $\mathrm{C}_{11} \mathrm{H}_{9} \mathrm{~F}_{2} \mathrm{NO}_{2}$ (225.19): C, 58.67; H, 4.03; N, 6.22; F, 16.87. Found: C, 58.45; H, 3.97; N, 6.18; F, 16.55 .

\section{Acknowledgments}

We are grateful to Italian MIUR (cofin 2000) for financial support.

\section{References}

1. Silvestri, R.; De Martino, G.; La Regina, G.; Artico, M.; Massa, S.; Vargiu, L.; Mura, M.; Loi, A. G.; Marceddu, T.; La Colla, P. J. Med. Chem. 2003, 46, 2482.

2. Corbett, J. W.; Ko, S. S.; Rodger, J. D.; Jeffrey, S.; Bacheler, L. T.; Klabe, R. M.; Diamond, S.; Lai, C.-M.; Rabel, S. R.; Saye, J. A.; Adams, S. P.; Trainor, G. L.; Anderson, P. S.; Erickson-Viitanen S. K. Antimicr. Ag. \& Chemoth. 1999, 43, 2893.

3. Corbett, J. W.; Ko, S. S.; Rodger, J. D.; Geahart, L. A.; Magnus, N. A.; Bacheler, L. T.; Diamond, S.; Jeffrey, S.; Klabe, R. M.; Cordova, B. C.; Garber, S.; Logue, K.; Trainor, G. L.; Anderson, P. S.; Erickson-Viitanen S. K. J. Med. Chem. 2000, 43, 2019.

4. Masashi, K.; Naohito, O. JP Application 97-3289, 1998.

5. Masashi, K.; Naohito, O. Eur. Pat. EP 787,728, 1997.

6. Robinson, B. The Fischer Indole Synthesis, J. Wiley and Sons: Chichester, New York, NY, 1982.

7. Heath-Brown, B.; Philpott, P. G. J. Chem. Soc. 1965, 7185.

8. Kissmann, H. M.; Farnsworth, D. W.; Witkop, B. J. Am. Chem. Soc. 1952, 74, 3848.

9. Clark, R. B.; Muchowski, J. M.; Fischer, L. E.; Filippin, L. A.; Repke, D. B.; Souchet, M. Synthesis 1991, 871.

10. Allen, D. A. Synth. Commun. 1999, 29, 447.

11. Carretero, J. C.; Garcia Ruano, J. L.; Vicioso, M. Tetrahedron 1992, 48, 7373.

12. Clark, R. D.; Caroon, J. M. J. Org. Chem. 1982, 47, 2804.

13. Examples of reaction at the carbonyl of ethyl bromopyruvate: (a) Freter, K. J. Org. Chem. 1972, 37, 2010. (b) Helmut, M.; Ofenloch, R. German Patent DE-81-3147276, 1983.

14. Saulnier, M. G. ; Gribble, G. W. J. Org. Chem. 1982, 47, 757.

15. Reimann, E.; Hassler, T.; Lotter, H. Arch. Pharm. (Weinhem) 1990, 323, 255. 